\title{
FORMAÇÃO COM PROFESSORES DE EDUCAÇÃO BÁSICA UTILIZANDO A RELAÇÃO DE MENTORING INTEGRANDO RECURSOS TECNOLÓGICOS NO PLANEJAMENTO DE AULAS
}

\author{
Reinaldo Pereira de Aguiar ${ }^{1}$
}

Marli Teresinha Quartieri ${ }^{2}$

\begin{abstract}
Resumo: Este artigo vem socializar contribuiçôes que ocorreram no planejamento da prática pedagógica de professores, do Ensino Médio e dos Anos Finais do Ensino Fundamental em Sáo Francisco do Conde no Estado da Bahia, utilizando-se a relação de mentoring com o uso de recursos tecnológicos. A pesquisa que tem a temática de formação de professores, com cunho qualitativo, caracterizada como um estudo de caso, sendo utilizados os seguintes instrumentos de coleta de dados: entrevistas, questionários e observação participante. Os resultados constatados foram: a) Uso do aparelho móvel do celular como alternância à insuficiência, e até mesmo inexistência ao recurso tecnológico do computador; b) Mentoring pode auxiliar na integração de recursos tecnológicos no planejamento pedagógico; c) Uso do recurso tecnológico da rede social - o blog - construído para uma das Escolas. Assim, o desenvolvimento desse trabalho oportunizou ao pesquisador e pesquisadas na busca de novas práticas pedagógicas e um ensino-aprendizagem diferente.
\end{abstract}

Palavras-chave: Recursos Tecnológicos. Formação de Professores. Mentoring. Educação Básica.

\section{TRAINING WITH TEACHERS OF BASIC EDUCATION USING THE RELATIONSHIP OF MENTORING INTEGRATING TECHNOLOGICAL RESOURCES IN CLASSROOM PLANNING}

\begin{abstract}
This article comes to socialize contributions that have occurred in planning the pedagogical practice of teachers, of high school and final years of elementary schools in the city of São Francisco do Conde in Bahia State, using the mentoring relationship with the use of technological resources.
\end{abstract}

1 Mestrado em Ensino pela Universidade do Vale do Taquari - Univates, Brasil (2016). Secretário Executivo da Universidade da Integração Internacional da Lusofonia Afro-Brasileira - BA, Brasil.

2 Doutorado em Educação pela Universidade do Vale do Rio dos Sinos, Brasil (2012). Professora da Universidade do Vale do Taquari - Univates. 
The research has the thematic of teacher training, with qualitative, characterized as a case study, the following instruments of data collection are: interviews, questionnaires and participant observation. The findings were: a) use of cellular mobile device such as interchange to insufficiency, and even inexistence to the computer's technological resource; b) Mentoring can assist in the integration of technological resources in educational planning; (c) use of technological resource of the social network - blog - built to one of the Schools. Thus, the development of this work provided the researcher and researched in search of new pedagogical practices and a different teaching-learning.

Keywords: Technological Resources. Teacher training. Mentoring. Basic education

\section{INTRODUÇÃO}

A realidade do ser humano na contemporaneidade, neste início de século XXI, tem em seu habitat a influência da tecnologia, seja na segurança pública ou privada, no esporte, na saúde e principalmente presente na educação. Neste sentido, os PCNs (Parâmetros Curriculares Nacionais) afirmam que o professor deve ser um instigador e mediador de informações aos discentes objetivando a formação de indivíduos críticos e reflexivos, inclusive trabalhando com o senso crítico dos discentes (BRASIL, 1998).

Para integrar este indivíduo no mercado profissional, a educação é considerada como meio fundamental. Entretanto, os processos de ensino e de aprendizagem dependem de algumas variáveis: do aluno, ao qual é o objeto de informação e conhecimento; do próprio conhecimento que os interlocutores almejam buscá-los; e do mediador da informação, que neste caso é o professor (BRASIL, 1997). O profissional da educação deve sempre inovar a prática pedagógica dinamizando suas aulas em contexto à realidade do aluno, bem como utilizar recursos tecnológicos. Para Valente (1999), a tecnologia constitui uma ferramenta importante para educandos, educadores e profissionais da educação.

Diante deste contexto surgiu o interesse em mediar encontros de formação para professores da Educação Básica dos Anos Finais do Ensino Fundamental e Ensino Médio de duas Escolas Públicas do Município de São Francisco do Conde na Bahia. A realização da pesquisa iniciou com um questionário distribuído para todos os professores das referidas escolas para verificar os desejos e anseios pelo manuseio de tecnologias. Após análise e averiguação dos resultados deste instrumento, observamos o interesse e a necessidade de capacitação para integrar os recursos tecnológicos na prática pedagógica. Logo após, foi realizado convite para encontros de formação com professores que lecionam as disciplinas de Língua Portuguesa destas duas escolas, totalizando doze docentes. No entanto, apenas 3 (três) destes profissionais aceitaram participar dos encontros e foram identificados neste texto como P1, P2 e P3.

Nestes encontros de formação foram trabalhadas as temáticas: as redes sociais - o blog e o facebook, a webquest e os aplicativos para construção de jornal ou informativos. Utilizamos a metodologia do mentoring na mediação dos encontros para interagir com os professores. Assim, no desenvolvimento deste trabalho responderemos à questão: quais contribuições ocorrem no planejamento da prática 
pedagógica, após a participação em encontros de formação continuada, utilizandose a relação de mentoring e com foco em recursos tecnológicos?

\section{REFERENCIAL TEÓRICO}

$\mathrm{Na}$ formação do professor, enfatiza Nóvoa (2009) que o ensino e a aprendizagem devem ter foco no contexto social e processos de desenvolvimento do indivíduo. No entanto, os PCNs mencionam que a educação no Brasil ainda não tem nexo entre a teoria e prática (BRASIL, 2000). Almeida (2006, p. 179) reforça que a formação de professores é "[...] uma das pedras angulares imprescindíveis a qualquer intento de renovação do sistema educativo".

Estudos apontam que a formação de professores acontece de duas formas: formação inicial e continuada. A formação inicial de professores no Brasil teve a origem no século XIX, com o surgimento das escolas normais, formando os docentes para as primeiras letras, e a partir da Lei de Diretrizes e Bases da Educação - LDB (BRASIL, 1996, art. 61-62), no:

Art. $61^{\circ}$. A formação de profissionais da educação, de modo a atender aos objetivos dos diferentes níveis e modalidades de ensino e às características de cada fase do desenvolvimento do educando, terá como fundamentos:

I - a associação entre teorias e práticas, inclusive mediante a capacitação em serviço;

II - aproveitamento da formação e experiências anteriores em instituições de ensino e outras atividades.

Art. $62^{\circ}$. A formação de docentes para atuar na Educação Básica far-se-á em nível superior, em curso de licenciatura, de graduação plena, em universidades e institutos superiores de educação, admitida, como formação mínima para o exercício do magistério na educação infantil e nas quatro primeiras séries do Ensino Fundamental, a oferecida em nível médio, na modalidade Normal.

A formação de professores é de extrema importância para dinamizar e enriquecer os educandos com a prática pedagógica, seja na formação inicial, obtida através dos Cursos de Licenciatura; ou, na formação continuada por intermédio de qualificação por meio de cursos de pós-graduação ou aperfeiçoamento. Segundo Gatti, Barreto e Afonso André (2011) a qualificação quando eficaz permite ao profissional ter uma formação com foco nas dificuldades enfrentadas no exercício da profissão. Ainda, quanto à formação de professores, Nóvoa (2009) enfatiza que, para a formação do profissional ter bons resultados é necessário observar e caracterizar algumas competências, tais como: a) o conhecimento, aos profissionais da docência cabe construir práticas pedagógicas que direcionem ao ensino e aprendizagem; b) a cultura profissional, que se adquire na instituição com a integração com os colegas de trabalho, mais e menos experientes, desenvolvendo trabalhos multidisciplinares; c) o tato pedagógico, que se refere à mediação de novos conhecimentos com a participação dos discentes nas aulas; d) o trabalho em equipe, que o professor deve utilizar de forma colaborativa em projetos da escola e; e) o compromisso social, em que o professor necessita convergir, integrar os princípios, os valores, a inclusão e a diversidade cultural nas aulas e fora do ambiente escolar. 
Para Nóvoa (2009), a formação na contemporaneidade deve abranger a realidade do discente. Assim, o uso das tecnologias em sala de aula pode ser uma forma de dinamizar a didática no ambiente escolar. Valente (2005) comenta que nesta época de uso de recursos tecnológicos, para o profissional da educação é importante ter o conhecimento pedagógico e técnico com a temática da tecnologia. Diante deste contexto, os encontros de formação ofertados tiveram o intuito de problematizar conhecimentos quanto: a metodologia da pesquisa na internet - a webquest, as redes sociais - o blog e o facebook, além dos aplicativos para construção de jornal ou informativo.

$\mathrm{Na}$ realização dos encontros com as três professoras, utilizamos a relação de mentoring, na qual há as personagens do: mentor e mentorado. O primeiro, aquele que tem um maior conhecimento em determinada área específica. Por outro lado, o mentorado ou mentoreado é o profissional iniciante quanto ao conhecimento da temática abordada. O mentor tem em seu processo o papel de escutar, ajudar, auxiliar e ampliar as ideias em seus direcionamentos como mediador, na relação entre os participantes do programa, no diálogo e construção de novos conhecimentos (VERGARA, 2013). De acordo com Botti e Rego (2008) ao mentor, que é um profissional experiente, cabe guiar, orientar e aconselhar ao mentoreado ou mentorado. Nesta relação entre as personagens há troca, reciprocidade, confiança e parceria na busca de um desenvolvimento amplo no plano interpessoal, psicossocial, educacional e profissional. O mentor tem sua história baseada na:

[...] personagem da Odisséia, poema escrito por Homero no século VIII antes de Cristo. Esse poema conta a história do retorno do rei Ulisses (ou Odisseu) a sua terra, Ítaca, após a vitória na guerra de Tróia. Mentor é amigo e conselheiro do rei. Quando partiu para a guerra, Ulisses confiou sua mulher Penélope e seu filho Telêmaco a Mentor. Passaram-se 20 anos; a família de Ulisses está humilhada e cerceada pelos pretendentes ao trono de Ítaca (BOTTI; REGO, 2008, p. 368).

No programa de mentoring é observada a relação de confiança entre o mentor e Ulisses, assim surgiu o nome mentor. São pessoas que expressam uma maior experiência pessoal e profissional; orientando, auxiliando e ajudando aos mais jovens, ou seja, inexperientes em determinada área. No caso deste estudo, os professores participantes - os mentorados - estavam iniciando seus estudos em relação ao uso de recursos tecnológicos, em particular na disciplina de Língua Portuguesa.

\section{PERCURSO METODOLÓGICO}

O desenvolvimento desta pesquisa foi realizado com professores de duas Escolas de Ensino Básico do Município de São Francisco do Conde no Estado da Bahia. Estas instituições foram denominadas de Escola 1 e Escola 2. A primeira dispõe de Ensino Médio, enquanto a segunda, oferta Anos Finais do Ensino Fundamental ( $6^{\circ}$ ao $9^{\circ}$ ano), ou Ensino Fundamental II. Foram convidados doze professores de ambas as escolas, mas apenas três destes confirmaram a participação 
(as professoras aqui denominadas de P1, P2 e P3), alterando o roteiro inicial de Curso de Formação para Encontros de Formação, devido ao número reduzido de participantes. Denota que os métodos de pesquisas utilizadas são: pesquisa qualitativa, com estudo de caso, utilizando observação participante e questionários individuais.

Esta pesquisa teve o cunho qualitativo, tendo em vista os instrumentos utilizados e a necessidade de estar presente no ambiente de pesquisa realizando observações, questionamentos e interagindo com o público pesquisado, tendo algumas de suas características:

$\left.1^{a}\right)$ A pesquisa qualitativa tem o ambiente natural como fonte direta dos dados e o pesquisador como instrumento-chave;

$[\ldots]$

$\left.2^{a}\right)$ A pesquisa qualitativa é descritiva;

$[\ldots]$

$3^{a}$ ) Os pesquisadores qualitativos estão preocupados com o processo e não simplesmente com os resultados e o produto;

$[\ldots]$

$\left.4^{a}\right)$ Os pesquisadores qualitativos tendem a analisar seus dados indutivamente; $[\ldots]$

$\left.5^{a}\right)$ O significado é a preocupação essencial na abordagem qualitativa (BOGDAN, 1994, p. 27-30).

No fato de ter utilizado de forma descritiva os dados, as observações e observando in locu. É uma pesquisa também caracterizada como um estudo de caso, na modalidade observação participante.

1. O estudo de caso é uma investigação empírica que

- investiga um fenômeno contemporâneo em profundidade e em seu contexto de vida real, especialmente quando os limites entre o fenômeno e o contexto não são claramente evidentes (YIN, 2010, p. 39).

Para o autor supra, o estudo de caso proporciona um breve conhecimento individual e até mesmo grupal na organização e na forma social do fenômeno ou situação observada. Nesta pesquisa, os instrumentos de coleta de dados utilizados foram: questionários, observação participante (gravação em áudio, fotografias) e entrevista individual. O primeiro instrumento, o questionário, teve a função de nortear o direcionamento dos encontros de formação. Em efeito:

O questionário é a forma mais usada para coleta de dados, pois possibilita medir com exatidão o que se deseja. A finalidade do questionário é obter, de maneira sistemática e ordenada, informações sobre as variáveis que intervém em uma investigação, em relação a uma população ou amostra determinada (FONSECA 2009, p. 36).

Para Gil (1999) enfatiza que o questionário apresenta algumas vantagens em relação à entrevista como: a) pode ser enviado para qualquer área geográfica através dos correios; b) garante o anonimato das pessoas; e c) momento oportuno 
para resolver o objetivo relacionado à pesquisa com questões abertas ou fechadas. Ao final dos encontros, realizamos novamente questionamentos aos participantes desta pesquisa, através de entrevistas. Fonseca (2009, p. 36) define a entrevista como sendo

[...] uma comunicação verbal entre duas ou mais pessoas, com um grau de estruturação previamente definido, cuja finalidade é a obtenção de informações de pesquisa. É uma conversa orientada para um objetivo definido, como receber informações relacionadas a um determinado assunto.

Segundo Lakatos e Marconi (2003) as entrevistas subdividem-se em: entrevista padronizada ou estruturada, despadronizada ou não-estruturada e painel. Nesta pesquisa utilizamos a entrevista estruturada com roteiro pré-estabelecido para obter o maior número de informações para a pesquisa. E assim iniciamos o trabalho com as pesquisadas em ação nas atividades de formação de professores com o uso de recursos tecnológicos na relação de mentoring.

Com as pesquisadas P1 e P2, de forma individual, trabalhamos um total de quatro encontros. No primeiro encontro adotamos um questionário com sondagem sobre o uso de recursos tecnológicos, e ao decorrer deste encontro, logo após o teste de sondagem utilizamos a temática das redes sociais: o facebook e o blog, trabalhando o texto: "Como usar as redes sociais a favor da aprendizagem" (VON STAA, 2011).

No segundo encontro continuamos com o uso das redes sociais em sala de aula, enfatizamos sobre o Projeto de Lei $\mathrm{n}^{\circ}$ 16.724/2007 de autoria do Deputado Estadual João Carlos Bacelar que dispõe sobre a proibição do uso de equipamentos eletroeletrônicos nas escolas do Estado da Bahia, no entanto, este projeto foi arquivado em 2 de fevereiro de 2015. E, neste encontro, também dialogamos sobre o uso de recursos tecnológicos, que não devemos pensar somente em computadores, pois existem outros recursos que podem ser utilizados, como por exemplo, o aparelho móvel do celular. Abordamos a temática da metodologia da pesquisa na internet "a webquest" fazendo demonstrações de como construí-la podendo ser utilizada em situações-problema para o ensino e a aprendizagem (DODGE, 1995).

No terceiro encontro trabalhamos com aplicativos na construção de jornais e informativos, bem como demonstramos a importância de trabalhar com o jornal na Língua Portuguesa. Também destacamos que o jornal contém inúmeros outros gêneros textuais como: editorial, texto jornalístico e notícias de opinião. Trabalhamos os aplicativos $\mathrm{Br}$ Oficce Draw e o Scribus como sendo softwares livres (podendo utilizar todas as funções do software), além do Microsoft Publisher como sendo um software proprietário (tendo a necessidade de realizar pagamento para usufruir de algumas funções do software) no qual o usuário necessita realizar compra para utilizar todas as funções. E no quarto encontro, além de expor modelos de jornais, sua importância e praticá-los com as pesquisas, planejamos uma aula para ser desenvolvida com os discentes utilizando umas das temáticas abordadas nos encontros. Para Valente (1999) e Ribeiro et al (2007) o uso de recursos tecnológicos 
em sala de aula possibilita um desenvolvimento de uma aula inovadora, integradora com o contexto social do aluno.

Com a professora $\mathrm{P}$, que participou de apenas dois encontros, abordamos as temáticas: rede social e o blog. Esta professora ficou bastante interessada no blog e já utilizava o aplicativo da rede social o "whatsapp” com todos os discentes das turmas que ministrava aulas. Orientamos que utilizasse com mais frequência esta ferramenta, aproveitando os diálogos dos alunos com gêneros textuais, além de indicar sites, links, fontes de pesquisas, entre outros. Ao final dos encontros, esta professora solicitou que realizássemos postagens no blog da Escola, mas também deixamos certos de que a escola de que as professoras poderiam fazer esta atividade para desenvolver a prática.

Figura 1 - Postagem de matéria no blog desenvolvida em sala aula pela professora P3 com os alunos

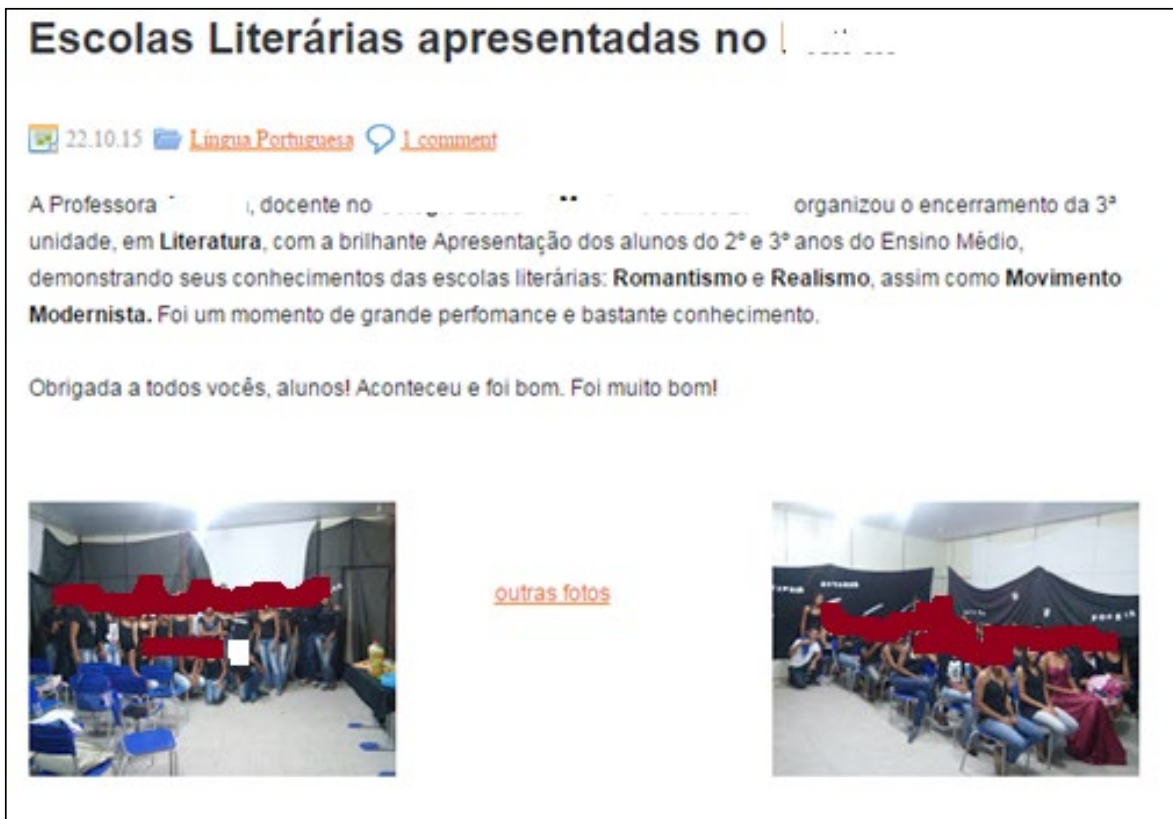

Fonte: blogger da Escola 1

Salientamos que nos encontros foram oportunizados momentos de troca de experiências, leituras e discussões, possibilitando a relação de confiança, segurança e partilha entre mentor e mentorado (VERGARA, 2013). Nos encontros observávamos a reação, as palavras das pesquisadas, deixava um ambiente natural para as perguntas e comentários.

Neste contexto, acreditamos que, após a obtenção dos dados, de acordo com Chizzotti (2001), e análise dos resultados advindos dos instrumentos que selecionamos como: questionários, entrevistas, observações e gravações, obtivemos subsídios para responder a questão de pesquisa: Quais contribuições ocorrem 
no planejamento da prática pedagógica após a participação em encontros de formação continuada, utilizando-se a relação de mentoring e com foco em recursos tecnológicos?

\section{RESULTADOS E DISCUSSÓES}

Considerando o objetivo deste trabalho e após a análise dos dados coletados, por meio dos instrumentos de pesquisa utilizados, podemos inferir três resultados: a) Uso do aparelho móvel do celular como alternância a insuficiência e até mesmo a inexistência do recurso tecnológico do computador; b) Mentoring pode auxiliar na integração de recursos tecnológicos no planejamento pedagógico; c) Uso do recurso tecnológico da rede social - o blog - construído para a Escola 1 pelo pesquisador, com idealização de P2 e P3. A seguir apresentaremos comentários pertinentes sobre estes resultados que emergiram do material de pesquisa, bem como sua análise.

a) Uso do aparelho móvel do celular como alternância a insuficiência e até mesmo inexistência do recurso tecnológico do computador.

A complexidade do uso das tecnologias na educação na opinião de Moran (2012) apresenta algumas situações: i) muitas escolas não têm sequer recursos tecnológicos e nem se fala em internet; ii) outras escolas já disponibilizam sites, blogs, grupos nas redes sociais, além de acesso à internet e ao ambiente virtual; iii) outras escolas preferem investir em projetos, pois desconfiam do uso das tecnologias por temerem o novo, e os profissionais não correspondem ao objetivo do projeto; iv) têm escolas que empolgam-se com as tecnologias numa visão otimista e têm salas equipadas com ferramentas tecnológicas, mas foca no ensino, no professor e no conteúdo; v) outras escolas incorporam as tecnologias de forma presencial ou semipresencial objetivando competir e incluir no projeto pedagógico da escola.

Nas Escolas 1 e 2, existem poucos recursos tecnológicos e estes são pouco utilizados. Na Escola 1 tem alguns computadores, TVs pendrive e data show, mas os computadores no laboratório de informática não estão funcionando. E, na Escola 2 não tem laboratório de informática, nem computadores para professores e alunos. No entanto, quando se fala em tecnologias não se pode pensar apenas nestes recursos, pois o professor pode utilizar a tecnologia móvel do aparelho do celular para auxiliar no ensino e na aprendizagem. Assim, durante os encontros de formação foram exploradas as funcionalidades deste aparelho, tais como o acesso a internet, fotografias, filmagens e uso das redes sociais e aplicativos.

$\mathrm{Na}$ Escola 2, de acordo com P1, "A escola não dispõe de recursos tecnológicos para utilizar em sala de aula, mas de acordo com a instrução do mestrando nos Encontros de Formação irei utilizar o recurso tecnológico do celular". E com isso, P1 utilizou o celular para fotografar, gravar vídeos e realizar pesquisas. A seguir, na Figura 2 um trabalho da professora $\mathrm{P} 1 \mathrm{com}$ os discentes da $8^{\mathrm{a}} \mathrm{A}$, utilizando o celular com os alunos. 
Figura 2 - Atividades na construção do jornal e a empolgação de P1
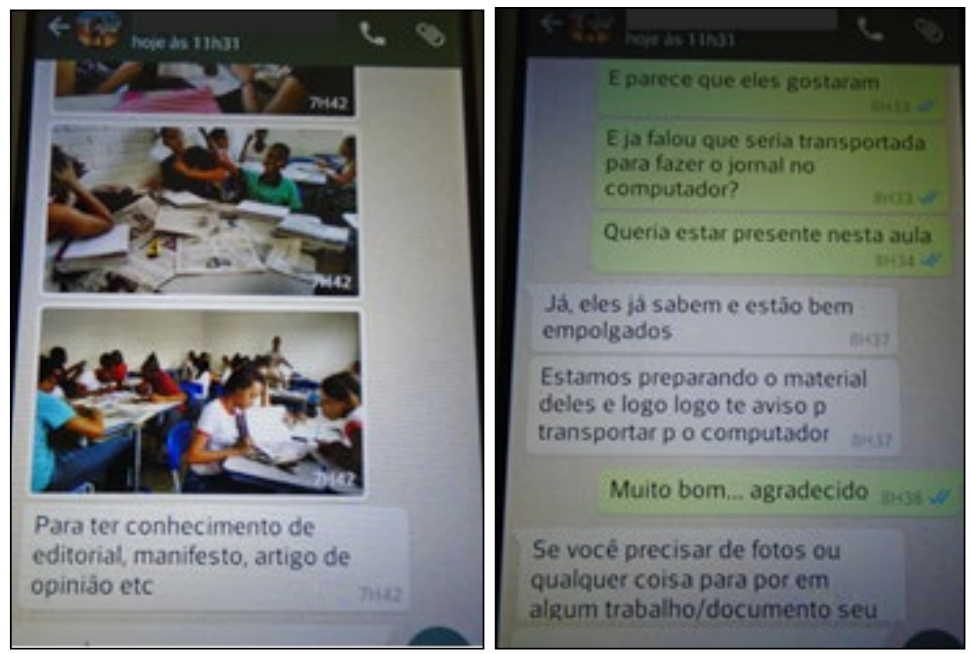

Fonte: Print screen na rede social Whatsapp, dos autores (2015).

A Professora P1 realizou atividades com o uso do aparelho móvel do celular e documentou, fotografando as atividades realizadas na sala e enviou para o nosso whatsapp. Assim, acompanhamos o desenvolvimento da prática pedagógica em sala de aula desta professora. Segundo Brossard (2014, p. 9) "A aprendizagem móvel é um ramo da TIC [Tecnologia da Informação e Comunicação] na Educação". A autora ainda enfatiza alguns benefícios desta aprendizagem móvel, como: facilitar a aprendizagem individualizada em qualquer lugar e momento; assegura o uso produtivo do tempo em sala de aula; cria uma ponte entre a aprendizagem formal e a informal fazendo uma ligação e; auxilia estudantes com deficiências de aprendizagem e apoia a aprendizagem fora da sala de aula.

Salientamos que a professora $\mathrm{P} 1$, teve alguns problemas durante a realização das aulas práticas, pois na escola o uso do aparelho móvel do celular é proibido. Assim, das quatro aulas planejadas para a atividade prática com os alunos, realizou apenas duas aulas. Ela comentou sua insatisfação com esta proibição, pois para ela o celular pode e deve ser usado para fins pedagógicos nas aulas.

A professora P2 utilizou o celular de propriedade dos alunos para pesquisas em sala de aula, objetivando encontrar poesias, analisar e selecioná-las. Solicitou que os alunos continuassem esta atividade fora da sala de aula. Ressaltamos que esta atividade seria direcionada para a construção de um jornal, mas a Coordenação da Escola 1 propôs a realização do projeto do Festival 2015 com escolas da região que o Município realiza anualmente. Assim, esta docente, direcionou as poesias para este evento, sendo as mesmas premiadas como as melhores poesias do festival.

A professora P3 utiliza o aplicativo da rede social o "whatsapp" e interage com os alunos, compartilhando links, sites de pesquisas e esclarecendo dúvidas. Esta professora solicitou ajuda, por meio do whatsapp, para que fosse realizada a 
postagem de informações e fotografias dos alunos na apresentação sobre Literatura no blog construído para a Escola 1, conforme exposto na Figura 3.

Figura 3 - Auxílio no uso do blog da Escola 1
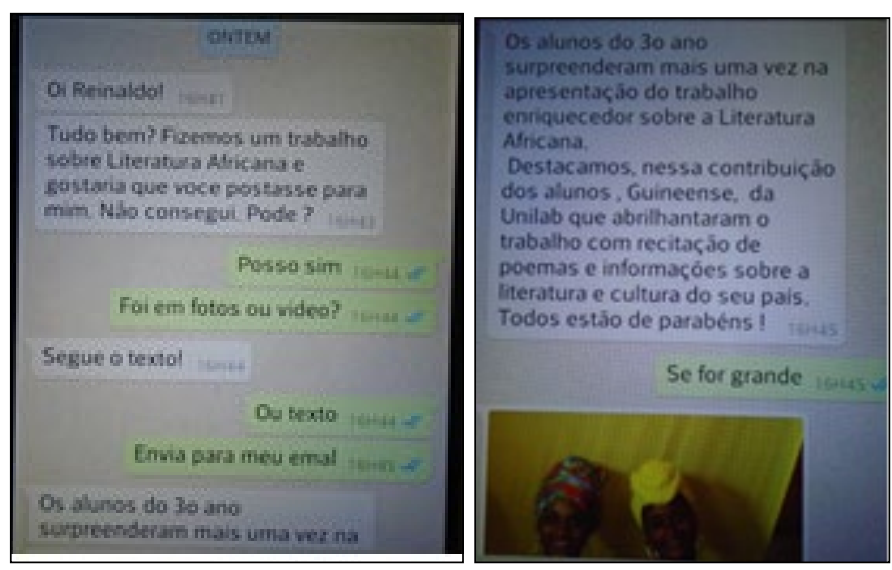

Fonte: Print screen do aplicativo whatsapp, dos autores (2015).

O diálogo, por meio do whatsapp, demonstra que no blog da Escola 1seriam postadas as fotografias das apresentações realizadas em aula e que os alunos teriam a necessidade de fazer comentários. Assim, o blog é um diário em que os alunos acessam conteúdos de seu interesse, o que pode auxiliar na aprendizagem.

As professoras P2 e P3 opinaram quanto ao uso da rede social - o facebook. A pesquisada P2 comentou: "Não tenho perfil no facebook". No entanto, quando ela falou em sala de aula sobre isso, ficou surpresa porque todos os alunos tinham perfil no facebook. Já a professora P3, respondeu: "Eu tenho o perfil no facebook, no entanto não passo para os alunos, pois entendo que o facebook é algo familiar sendo, portanto particular. E, ainda enfatizo que na sala de aula devo agir diferente dos meus momentos de lazer, de família, de descanso". Para a professora P3 o facebook é de utilidade pessoal e familiar. Entretanto, quando informamos que poderiam ser trabalhados diversos conteúdos e começamos a listá-los, as professoras P2 e P3 continuaram a usar a criatividade e expuseram que poderiam ser trabalhados outros conteúdos programáticos, tais como: "denotação e conotação; figuras de linguagem; crase; ortografia e tipologia textual" (P2 e P3). Para Minhoto (2012) a familiaridade dos alunos com a rede social o facebook, pode possibilitar a atualização de novos conhecimentos sobre diversos temas de estudo.

Para os educadores da Escola 1 e 2, quando se falava, inicialmente, em recursos tecnológicos, somente consideravam o computador como recurso tecnológico. Expressavam que não usavam recursos tecnológicos porque o laboratório de informática não estava em funcionamento. No entanto, a tecnologia de ontem, continua sendo um recurso tecnológico, não usado tanto quanto atualmente, mas continua sendo uma tecnologia, vamos dizer, um pouco menos utilizada. Por exemplo, um livro, ontem, que seria somente impresso, hoje se apresenta na 
forma digital e virtual, sendo também considerado um recurso tecnológico, antes e atualmente. Assim, após as discussões nos encontros de formação, identificaram outros recursos, tais como: o rádio, a TV, o aparelho móvel de celular, o data show, o notebook, o tablet, a TV pen-drive, entre outros (MORAN, 2012).

Diante das reflexões, P2 expressou a importância de tais recursos nos processos de ensino e de aprendizagem, pois podem auxiliar ao indivíduo no desenvolvimento de um ser crítico, reflexivo e construtor de novos conhecimentos. De acordo com Moran (2012) para que isto aconteça é importante que o professor ao usar estes recursos em sala de aula o faça com objetivos claros e com atividades diferenciadas.

Os encontros de formação realizados com os mentorados proporcionaram o desenvolvimento em sala de aula do uso do aparelho móvel de celular, como alternativa à insuficiência de computadores nas escolas. Aliado, as redes sociais também foram utilizadas como uma metodologia possível para desenvolver alguns conteúdos programáticos, além de permitir uma maior interatividade entre os discentes e professores.

b) Mentoring pode auxiliar na integração de recursos tecnológicos no planejamento pedagógico.

O programa de mentoria torna-se eficaz quando o mentor consegue criar um ambiente que seja aceito e integrado pelo mentorado (AMADO, 2007). Neste contexto, reforça Vergara (2013) que na relação de mentoring deve haver: colaboração, auxílio, compartilhamento e integração de conhecimentos. Podemos inferir que houve esta parceria com as participantes da pesquisa, as professoras P1, P2 e P3. Destacamos que a professora P3, a qual participou de apenas dois encontros comentou: "Fiquei bastante satisfeita com os encontros, gostaria de ter participado de todos os encontros ministrados pelo mestrando". Realizamos acompanhamento sistemático com as três professoras para auxiliar no planejamento de aulas com recurso tecnológico, bem como durante o desenvolvimento de algumas atividades. A Figura 4 retrata os encontros de formação entre o mentor e mentorado.

Figura 4 - Encontros de Formação entre mentor e mentoradas
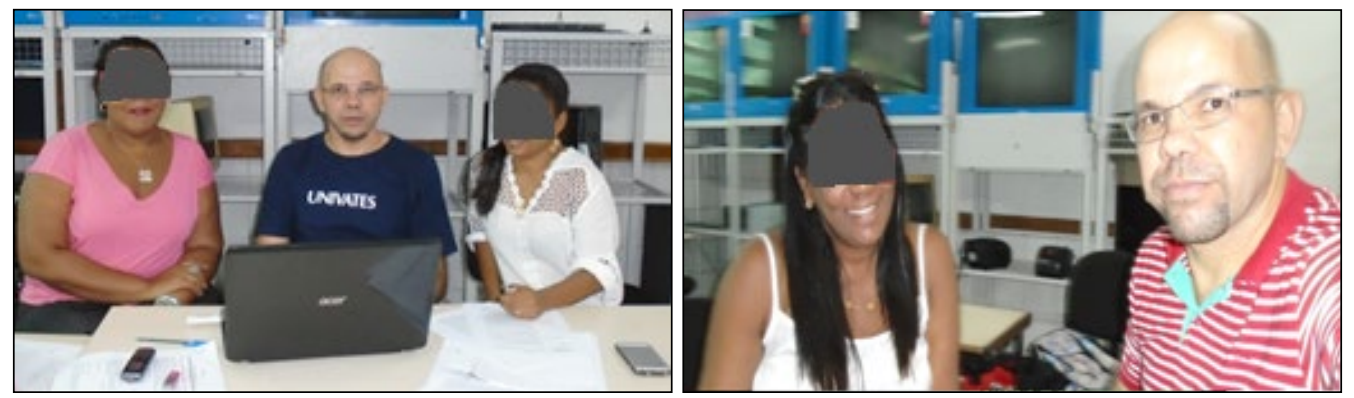

Fonte: Dos autores (2015). 
No Figura 4 visualizamos o mentor no centro, porque às vezes as professoras não levavam notebook e assim, tínhamos que trabalhar em conjunto. E no papel de mentor realizava-se, muitas vezes, a demonstração da atividade, para que depois elas fizessem a atividade, objetivando a aprendizagem individual. Observávamos, acompanhávamos e orientávamos as docentes, deixando-as à vontade para, em caso de erro, esclarecer as dúvidas e saná-las com o papel de colaborador, de ajuda e auxílio.

No referido programa de mentoria, de acordo com Vergara (2013), o mentor deve auxiliar, dialogar, compartilhar e somar com instruções em busca de novos conhecimentos e inovação na prática pedagógica para com o interlocutor. Isso não significa que este professor, tenha mais experiência ou conhecimento do que aquele ao qual instruir, mas tem mais instruções didático-pedagógicas nesta área específica. Assim, durante os encontros com as três participantes foram proporcionados momentos em que elas falassem sobre seus desejos e angústias em relação ao uso de recursos tecnológicos em sala de aula. Procuramos neste momento realizar diálogos nos encontros em forma de parceria, esclarecimentos de dúvidas, sugestões de como utilizar as ferramentas tecnológicas da contemporaneidade que poderão somar no ensino e na aprendizagem. No início, percebemos que as professoras estavam "tímidas" quanto ao diálogo sobre o uso de tecnologias e em alguns momentos até constrangidas (quando realizamos alguns encontros com professora da Escola 1, juntamente com professora da Escola 2), mas com o passar dos encontros passaram a interagir e a ter confiança, bem como dialogando entre elas. Durante estes períodos de encontro presencial criamos no whatsapp um grupo em que trocávamos sugestões, perguntas e esclarecimentos de dúvidas. O grupo denominado "Formação e o computador" também auxiliou no agendamento dos nossos encontros de formação, bem como sobre indicações de atividades a serem executadas na aula prática com os alunos. Na Figura 5, exemplo de troca de conversa entre os participantes no grupo do whatsapp em que o propósito foi a indicação de fontes de pesquisas. 
Figura 5 - Sugestões de sites para pesquisa

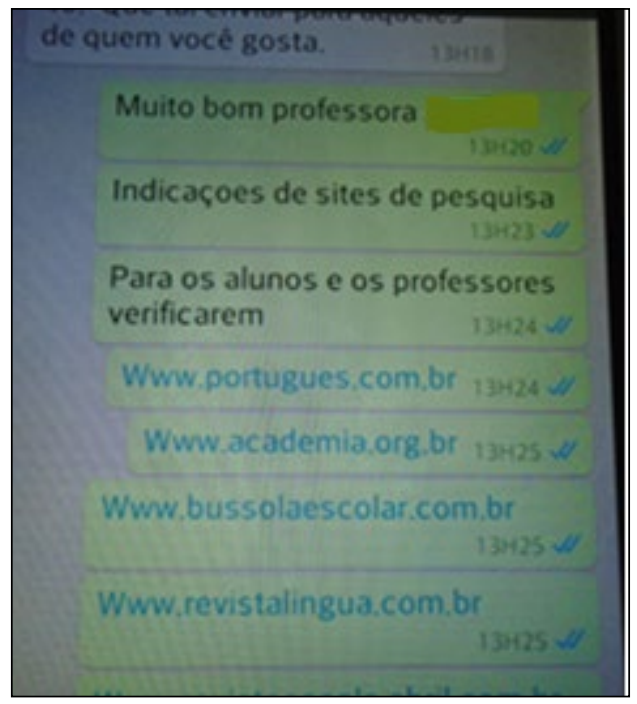

Fonte: Print screen da rede social, o aplicativo whatsapp, dos autores (2015).

O recurso tecnológico da rede social - whatsapp - foi um aplicativo bastante utilizado durante os encontros, tendo em vistas as habilidades das professoras para utilizá-la antes de iniciarmos nossas discussões. Entretanto, mesmo sabendo usar o whatsapp, percebemos que teriam necessidade de auxílio para uso desta ferramenta. Houve um momento que solicitamos às professoras que enviassem para nosso e-mail as mensagens do nosso grupo do whatsapp, porém nenhuma das três professoras enviou o e-mail. P1, em conversa posterior perguntou: "Como faço para enviar para e-mail as mensagens de whatsapp?" Então explicamos como ela deveria fazer, demonstrando os procedimentos necessários. Nesta situação fica evidente a presença da relação de mentoring com auxílio e colaboração. A professora P1 demonstrou confiança em relação ao mentor solicitando auxílio.

Em relação ao planejamento de aulas práticas para serem desenvolvidas com os alunos, este foi realizado individualmente e apenas com as professoras P1 e P2. Com P1 planejamos a produção de um jornal utilizando 4 aulas, sendo que duas aulas seriam realizadas sem o uso do computador e as outras duas aulas seriam para o laboratório de informática da Unilab. Já com P2 planejamos a produção de um jornal, transformando poesia em notícia e notícia em poesia. Também optou pela alternativa de que se não conseguisse produzir o jornal iria criar um blog para a Escola 1. Destacamos que estes momentos de planejamento foram de cumplicidade e ajuda mútua, pois ao mesmo tempo em que as auxiliávamos, comentavam sobre suas dificuldades e expectativas em relação a aplicação das referidas atividades. Aqui, novamente percebemos a importância da relação de mentoring, conforme evidenciado por Amado (2007) quando esta autora comenta sobre a necessidade de o mentor estar aberto as discussões e proporcionar aos mentorados confiança e possibilidade de expor suas angústias e avanços. 
As professoras relataram que inicialmente pensavam que os encontros seriam somente teoria, algo "chato" como os outros cursos. Ao final dos encontros os comentários foram: "O diálogo e a parceria entre mestrando e professoras contribuíram para a aprendizagem dos temas trabalhados nos encontros de formação e, além disso, eram esclarecidas as dúvidas através do whatsapp" (P1); "Os encontros proporcionaram um bom aprendizado, no entanto eu não tenho quase tempo para dedicar e desenvolver atividades em sala de aula com os recursos tecnológicos" (P2); "Participei de somente dois Encontros de Formação, mas gostaria bastante de ter participado de todos os encontros, mas mesmo assim irei utilizar o blog construído para a escola" (P3). Os relatos das professoras demonstram que os encontros de formação propiciados tiveram resultados proveitosos, mesmo que não houve a possibilidade de desenvolver todo o planejamento pensado. Durante o planejamento das práticas as professoras solicitavam ajuda, demonstravam suas angústias e anseios com o uso de recursos tecnológicos. Pelos depoimentos das docentes podemos inferir que a relação de mentoring auxiliou positivamente nesta etapa de planejamento, pois tínhamos uma relação de confiabilidade, auxílio, parceria, aceite, partilha e feedback entre os profissionais participantes.

c) Uso do recurso tecnológico da rede social - o blog - construído para a Escola 1 pelo pesquisador com idealização de P2 e P3.

Para Recuero (2009) o blog tem algumas funcionalidades para a educação como: disponibilizar textos, listar links e sites, meio de comunicação entre a comunidade escolar, interatividade e sociabilidade. Nos encontros demonstramos como se poderia construir e utilizar um blog, explicamos regras de direitos autorais, mostramos blogs de outras instituições de ensino como fonte de pesquisa e que poderiam expor os trabalhos da escola, da turma, ou da disciplina, valorizando o trabalho realizado pelos alunos e educadores. Assim, percebemos o interesse das professoras na criação de um blog para cada uma das escolas.

$\mathrm{Na}$ Escola 1, a professora P2, inicialmente gostaria de criar o jornal com seus alunos, por meio de recursos computacionais. Também comentou que se não conseguisse realizar esta atividade, iria construir um blog. Deixamos livre e algum tempo após a atividade de planejamento, com feedback através de mensagem no whatsapp (FIGURA 6), constatamos que a professora não conseguiu construir um blog conforme a atividade de planejamento. 
Figura 6 - Resposta de P2 quanto à realização da atividade de planejamento

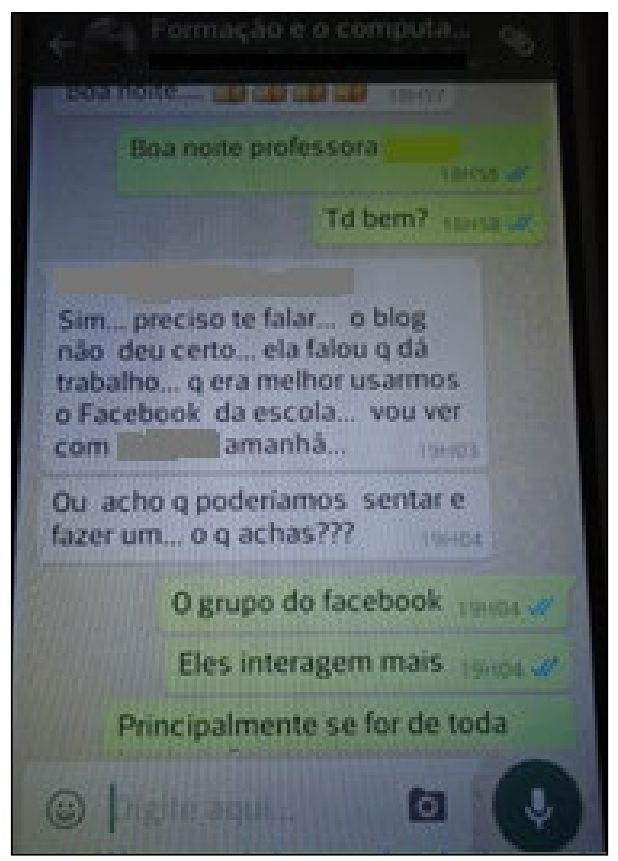

Fonte: Print screen do aplicativo whatsapp, dos autores (2015).

A mensagem na Figura 6 retrata a tentativa da professora P2 na construção do blog. Como ela não conseguiu criar o blog, como mentor e objetivando que a professora P2 executasse a atividade de planejamento, resolvemos auxiliar e conversar com a Direção e Coordenação da escola para a construção do blog. A gestão da Escola 1 ficou satisfeita com a proposta. Apesar de alguns professores terem um conhecimento básico sobre este recurso, mesmo assim, quase não utilizavam para dinamizar o processo de ensino e aprendizagem (RIBEIRO; CASTRO; REGATTIERI, 2007). Então foi proposto o auxílio para construção do blog e que ficaríamos administrando-o conjuntamente com a equipe da Escola 1, durante um período de 3 meses. Comentamos ainda que mesmo após este prazo, em caso de dúvidas, poderiam nos contatar.

Iniciamos a construção do blog com postagens e explicações de como realizar estas atividades, também utilizando o e-mail e um grupo no whatsapp como ferramenta de interatividade. Na Figura 7, demonstrações de algumas instruções de como realizar postagens no blog da Escola 1 enviadas para o e-mail das coordenadoras pedagógicas. 
Figura 7 - Instruções de postagem no blog através do e-mail

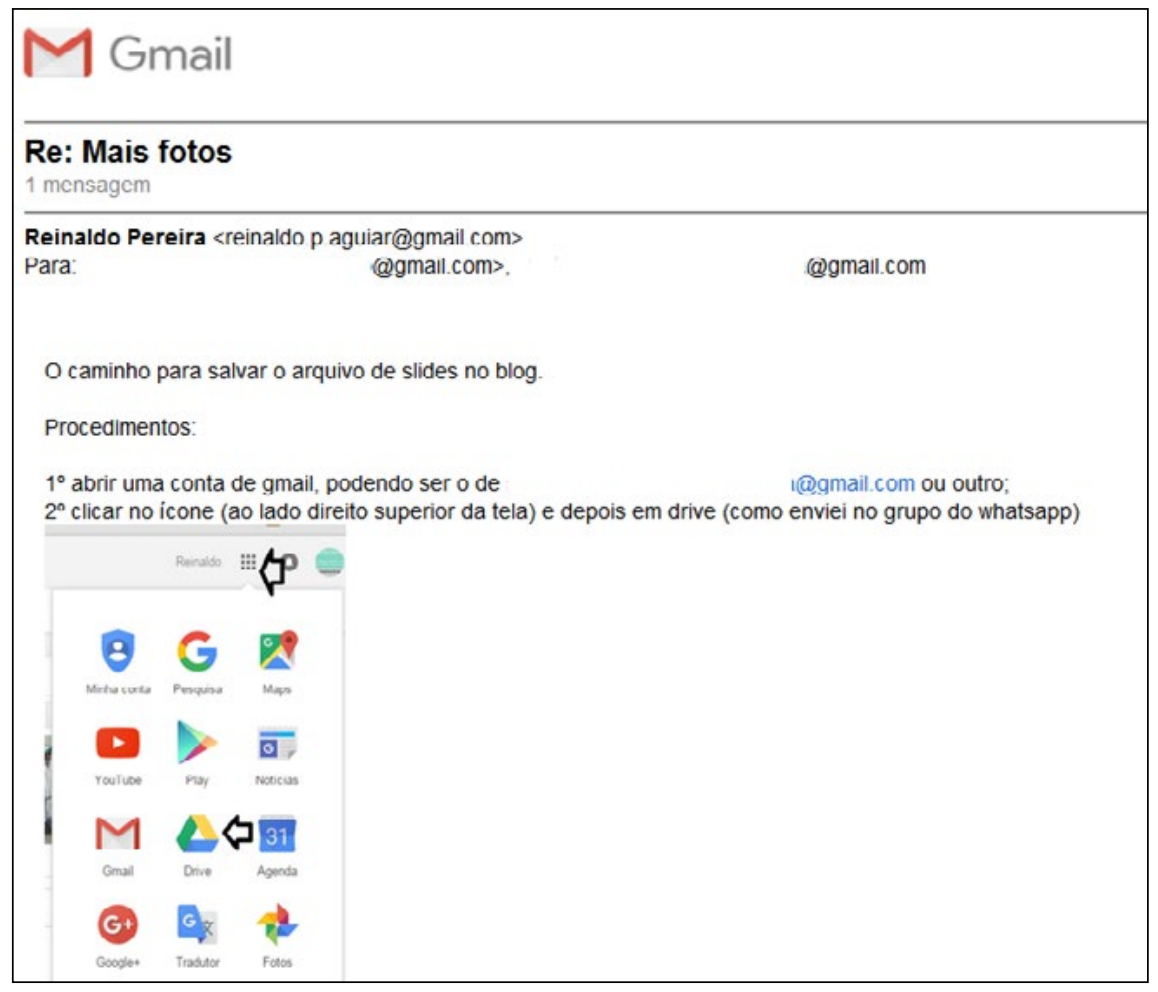

Fonte: Print screen na caixa de e-mail do Gmail, dos autores (2015).

$\mathrm{Na}$ elaboração do conteúdo do blog pensamos em informações sobre as disciplinas, disponibilização de sites de bibliotecas, dicionários, museus, sites de cursos, mas sempre enfatizando para a Escola 1, que seriam apenas sugestões, podendo serem modificadas e administradas de acordo com o planejamento e necessidade da escola, possibilitando utilizar este recurso como demonstração do ensino e aprendizagem de professores e alunos, respectivamente.

Para melhor localizar a Escola 1, cadastramos no google a escola, com endereço, localização no google maps, telefone e endereço do blog. E, atualmente, quando o internauta acessa a internet, o endereço do blog já aparece como sendo o primeiro link na lista de pesquisa no google, em digitando os temas: Colégio ou Escola 1 (nome da Escola 1). Em menos de 10 dias de publicação já contava com aproximadamente 1.500 visitas, inclusive com comentários das professoras participantes dos encontros.

O blog foi publicizado por meio das redes sociais, em especial em três grupos de facebook da cidade de São Francisco do Conde e cidades circunvizinhas como Santo Amaro, Madre de Deus e Candeias. As coordenadoras pedagógicas da referida escola solicitaram que fosse feito um informativo com o endereço do blog, descrevendo um pouco sobre as informações contidas no mesmo para 
ser distribuído aos professores da Escola. Salientamos ainda que a coordenadora responsável pelo Ensino de Jovens e Adultos (EJA) da escola 1, ficou bastante interessada em relação ao uso do blog e solicitou auxílio para divulgar o blog aos alunos da EJA. Então, informamos ao público da escola - discentes, professores, direção e coordenação - como realizar algumas postagens no blog para demonstrar um trabalho com eficiência e que tenha resultados eficazes. Destacamos que sempre que realizamos uma postagem devemos descrever um breve comentário sobre a informação do post, e se possível um breve vídeo ou relato do organizador e participante do evento ou apresentação. O blog é uma ferramenta de pesquisa e de aprendizagem para os discentes em todas as disciplinas e na Língua Portuguesa poderá usufruir de postagens de sites, dicionários, trabalhos realizados, ou seja, um diário com fontes de pesquisas.

Podemos inferir que a construção do blog e a explanação sobre as características e funcionalidades para o ensino e a aprendizagem na Escola 1 possibilitou que a comunidade escolar adquirisse novos conhecimentos. A coordenadora pedagógica da Escola 1 realizou o comentário sobre a importância do blog:

O blog é uma ferramenta nova, que quando bem "alimentado" torna-se fonte
de pesquisa extremamente rica que vai trazer novos conhecimentos para o
educador e o educando e haverá uma troca de informações que poderão ser
transformadas em conhecimento. Assim, não pode haver postagens no blog
somente de links, mas que possa fazer um breve resumo, devendo postar
textos e links que despertem a atenção e seja proveitosa a sua leitura para
construir novos conhecimentos.

Reforça a coordenadora pedagógica de que as postagens no blog não devem ser realizadas de qualquer forma, mas que desperte a atenção do leitor (blogueiro), podendo ser feito um breve resumo da matéria.

Destacamos que o blog construído para a escola 1 foi uma solicitação das professoras P2 e P3 da referida escola. Como teriam dificuldades para esta construção, como mentor dispusemos em auxiliá-las. Elas (mentoradas) explicitaram suas dificuldades, demonstrando mais uma vez a confiança no mentor. As professoras P2 e P3 encaminharam materiais para que fossem publicados no blog. Salientamos que durante este procedimento demonstramos às professoras os "passos" para realizar uma postagem.

\section{CONSIDERAÇÓES FINAIS}

Este texto teve como objetivo socializar os dados decorrentes de uma pesquisa que teve o intuito de investigar quais contribuições ocorrem no planejamento da prática pedagógica de professores do Ensino Médio e dos Anos Finais do Ensino Fundamental, utilizando-se a relação de mentoring, com foco no uso de recursos tecnológicos. Podemos inferir que os resultados encontrados com os instrumentos de coleta de dados (questionários, entrevistas e gravações) foram: a) uso do aparelho móvel do celular como alternância a insuficiência, e até mesmo inexistência ao recurso tecnológico do computador; b) mentoring pode auxiliar na 
integração de recursos tecnológicos no planejamento pedagógico; c) Uso do recurso tecnológico da rede social - o blog - construído para a Escola 1 pelo pesquisador, com idealização de P2 e P3.

Podemos concluir pelos resultados encontrados, que o uso de tecnologias na prática pedagógica depende de iniciativas dos profissionais da educação. Sendo assim é necessária a mudança do papel do educador na educação, ou seja, de uma aula tradicional com apenas o uso do lápis e giz, para uma aula inovadora que pode utilizar além destes instrumentos, outras tecnologias. Salientamos que ao falar em tecnologias não devemos focar somente em computador, mas expandir nossos "olhares", como o uso do aparelho celular utilizado pela pesquisadora P1 que teve um resultado que surpreendeu no desenvolvimento das duas aulas (P1, 2015).

Destacamos ainda que os encontros de formação utilizando-se o mentoring proporcionou uma relação de confiança, de auxílio, de trocas de experiências, de esclarecimentos de dúvidas e partilha de novos conhecimentos entre mentor e mentorado. Acreditamos que esta forma de relação possibilitou mais segurança aos mentorados em utilizar as tecnologias, aqui, mais especificamente, o celular, no planejamento, bem como no desenvolvimento da prática pedagógica.

\section{REFERÊNCIAS}

ALMEIDA, Maria Isabel de. Apontamentos a respeito da formação de professores. IN: BARBOSA, Raquel Lazzari Leite. Formação de educadores: artes e técnicas, ciências políticas. São Paulo: Editora UNESP, 2006.

AMADO, Nélia Maria Pontes. O professor estagiário de matemática e a integração das tecnologias na sala de aula: Tese. Universidade do Algarve (Faculdade de Ciências em Tecnologia), Faro, Portugal, 2007.

BOGDAN R, Biklen S. Investigação qualitativa em educação: uma introdução à teoria e aos métodos. Porto: Porto Editora, 1994.

BOTTI, Sérgio Henrique de Oliveira; REGO, Sérgio. Preceptor, supervisor, tutor e mentor: Quais são seus papéis? Rev. bras. educ. med. v.32, n.3, p. 368-373, jul/set. 2008.

BRASIL, Lei $\mathbf{n}^{\circ} \mathbf{9 . 3 9 4}$, de 20 de dezembro de 1996 (Estabelece as diretrizes e bases da educação nacional). Brasília: Congresso Nacional, 1996.

. Secretaria de Educação Fundamental. Parâmetros Curriculares Nacionais: Língua Portuguesa, Brasília: Ministério da Educação e do Desporto, 1997.

. Secretaria de Educação Fundamental. Parâmetros Curriculares Nacionais: terceiro e quarto ciclos do Ensino Fundamental: Língua Portuguesa/Secretaria de Educação Fundamental. Brasília: MEC/SEF, 1998.

Parâmetros Curriculares Nacionais: Ensino Médio. Brasília: MEC, 2000. 
BROSSARD, Rita (trad.). Diretrizes de Políticas para a Aprendizagem Móvel. Brasília: UNESCO, 2014.

CHIZZOTTI, A. Pesquisa em ciências humanas e sociais. São Paulo: Cortez, 2001.

DODGE, Bernie. Webquest: uma técnica para aprendizagem na rede internet. São Paulo: USP, 2006, Traduzido pelo Prof. Jarbas Novelino Barato, do Artigo Original: A

Technique for Internet - Based Learning , publicado em The Distance Educator, v.1, n 2, 1995, Acesso em: http://www.webquest.futuro.usp.br/artigos/textos_bernie.html

FONSECA, Regina Célia Veiga de. Metodologia do trabalho científico. Curitiba: IESDE Brasil S.A., 2009.

GATTI, Bernardete Angelina; BARRETO, Elba de Sá; AFONSO ANDRÉ, Marli Eliza Dalmazo. Políticas docentes no Brasil: um estado da arte. Brasília: UNESCO, 2011.

GIL, Antônio Carlos. Métodos e técnicas de pesquisa social. 5. ed. São Paulo: Atlas, 1999.

LAKATOS, Eva Maria; MARCONI, Marina de Andrade. Fundamentos de Metodologia Científica. 5. ed. São Paulo: Atlas, 2003.

MINHOTO, Paula Maria Lino Veigas. A utilização do Facebook como suporte à aprendizagem da biologia: estudo de caso numa turma do $12^{\circ}$ ano. Dissertação (Mestrado em Ensino das Ciências). Escola Superior de Educação, Bragança, 2012.

MORAN, José Manuel. A educação que desejamos: Novos desafios e como chegar lá. 5. ed. Campinas, SP: Papirus, 2012.

NÓVOA, Antônio. Professores: imagens do futuro presente. Lisboa, Portugal: EDUCA (Instituto de Educação Universidade de Lisboa Alameda da Universidade), 2009.

RECUERO, Raquel. Redes Sociais na Internet. Porto Alegre: Sulina, 2009.

RIBEIRO, Antonia; CASTRO, Jane Margareth de; REGATTIERI, Marilza Machado Gomes. Tecnologias na sala de aula: uma experiência em escolas públicas de Ensino Médio. Brasília: UNESCO/MEC, 2007.

VALENTE, José Armando. O computador na sociedade do conhecimento. Campinas, SP: UNICAMP/NIED, 1999

O salto para o futuro. Cadernos da TV-escola. Sede MEC, Brasília, 2005.

VERGARA, Sylvia Constant. Mentoria. In: Gestão de Pessoas. 13. ed. São Paulo: Atlas, 2013.

VON STAA, Betina. Como usar as redes sociais a favor da aprendizagem. Entrevista feita por Daniele Pechi. Revista Nova Escola: Abril, out. 2011.

YIN, R. K. Estudo de caso: planejamento e métodos. 4. ed. Porto Alegre: Bookman, 2010. 